\title{
Crystallite size evolution of aramid fibres aged in alkaline environments
}

\author{
G. Derombise ${ }^{1, *}$, L. Vouyovitch Van Schoors ${ }^{2}$, E. A. Klop ${ }^{3}$, A.H.M. Schotman ${ }^{3}$, G. \\ Platret $^{2}$, P. Davies ${ }^{4}$ \\ ${ }^{1}$ Laboratoire Régional des Ponts et Chaussées de Nancy, CETE de l'Est, Tomblaine, France \\ ${ }^{2}$ Materials Department, IFSTTAR, Paris, France \\ 3 Teijin Aramid BV, Arnhem, The Netherlands \\ ${ }^{4}$ Materials and Structures group, IFREMER, Plouzané, France \\ *: Corresponding author : G. Derombise, email address : guillaume.derombise@developpement-durable.gouv.fr
}

\begin{abstract}
:
Aramid fibres are high-performance materials proposed in geotextiles for alkaline ground reinforcement. To study their durability in such environments, accelerated ageing has been carried out at $\mathrm{pH} 9$ and at $\mathrm{pH} 11$ for up to one and a half years. First, the lateral and longitudinal crystallite sizes have been determined before and after ageing under these conditions by Wide-Angle $\mathrm{X}$-ray diffraction. Next, the tensile fracture surfaces have been observed after different ageing times by scanning electron microscopy. Finally, molecular weight changes have been evaluated by size exclusion chromatography. This study highlights the dependence of structural changes on the ageing conditions. A structural degradation scheme is proposed.
\end{abstract}




\section{Introduction}

Twaron fibres, produced by Teijin Aramid, are high performance fibres based on $\operatorname{poly}(p-$ phenylene terephtalamide) (PPTA, Figure 1) similar to Kevlar fibres [1]. Today they are being proposed in geotextiles for treated soil reinforcement. These applications require long term durability in alkaline environments.

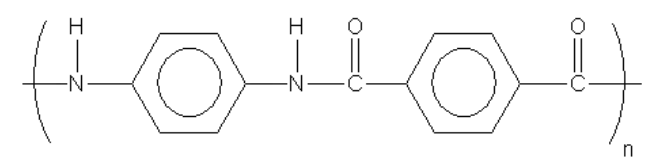

Figure 1: PPTA molecular structure.

The mechanical properties of PPTA fibres may be affected by exposure to water at acidic or basic conditions or at high temperatures $[2,3]$. It is known that hydrolysis involves a scission of the amide N-C linkage, yielding acid and amine functions (Figure 2) [2, 4].

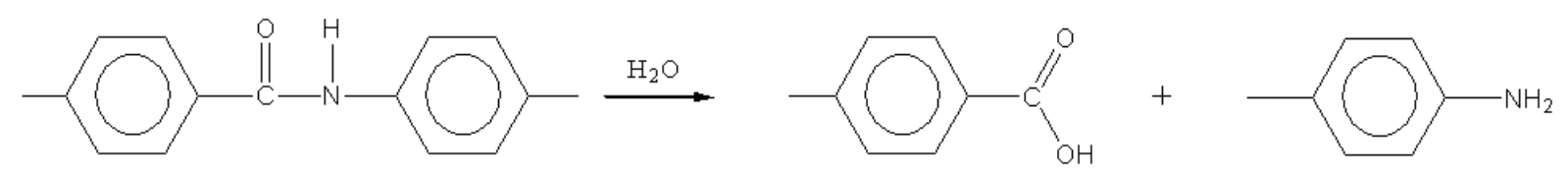

Figure 2: Hydrolysis of PPTA.

The structure and morphology of PPTA fibres have been studied extensively [5-10]. The highly crystalline and highly oriented structure of PPTA fibres has been shown to be composed of several superimposed structural levels, among which are the chain-ends and the crystallites arrangement [5-7], the fibrillar structure [5], the pleated sheet structure $[5,8,9]$ and the skin-core structure [5, 6, 10]. For example, Panar et al. [5] proposed a structure with a high proportion of extended chains passing through a periodic chain-end layer. Moreover, they highlighted a fibrillar structure, superimposed on the chain-ends structure, consisting of 600 
nm-wide fibrils oriented along the fibre axis and linked together by tie-fibrils. Finally, these authors showed that the fibrils are uniformly axially oriented in the skin region, whereas the fibrils are imperfectly packed and ordered in the core region. Riekel et al. [11] observed an improvement of the chain axis orientation for Kevlar fibres from the core to the skin using Xray microdiffraction. This gradient of orientation disappears upon tensile deformation [11]. In related X-ray microdiffraction work by Roth et al. [12], the presence of a discrete skin layer has been highlighted for different grades of Kevlar fibres.

Springer et al. [3] followed the evolution of the mechanical properties of Kevlar 49 and Twaron 1055 subjected to "aggressive" hydrolytic treatments, namely 4 days in $\mathrm{H}_{2} \mathrm{SO}_{4}$ (40 $\mathrm{wt} \%)$ at $90^{\circ} \mathrm{C}, 4$ days in $\mathrm{NaOH}(10 \mathrm{wt} \%)$ at $90^{\circ} \mathrm{C}$, and one day in water at $120^{\circ} \mathrm{C}$. They showed that both the modulus and tensile strength were affected, but the property drops were larger in acid and basic solutions than in a neutral environment. The tensile strength data were fitted by the following equation:

$$
\sigma=\sigma_{0}\left(\alpha_{1} \exp \frac{-t}{\tau_{1}}+\alpha_{2} \exp \frac{-t}{\tau_{2}}\right)
$$

where $\alpha_{1}$ and $\alpha_{2}$ represent the amounts, and $\tau_{1}$ and $\tau_{2}$ the decay times of two degradation processes. According to the authors, these two processes may be assigned to two different fibre regions (core and shell or crystalline and non-crystalline regions) or to structural elements being stressed differently (loose and taut tie molecules). They reported that the lateral apparent crystallite size (ACS) of Kevlar 49 fibres increases after 4 days in $\mathrm{H}_{2} \mathrm{SO}_{4}(40$ wt $\%)$ at $90^{\circ} \mathrm{C}, 4$ days in $\mathrm{NaOH}(10 \mathrm{wt} \%)$ at $90^{\circ} \mathrm{C}$ and one day in water at $180^{\circ} \mathrm{C}$. Their results reveal that the increase in the lateral ACS is accompanied by a decrease in the longitudinal ACS. For example, $\mathrm{ACS}_{110}$ increases by $8 \%$ and $\mathrm{ACS}_{200}$ increases by $5 \%$, whereas $\mathrm{ACS}_{002}$ decreases by $3 \%$ after 4 days in $\mathrm{NaOH}(10 \mathrm{wt} \%)$ at $90^{\circ} \mathrm{C}$. The authors suggested that these 
structural changes may be attributed to the breakage of the tie-molecules passing through consecutive crystallites mentioned in Panar et al. and Li et al.'s structural models [5, 7]. Springer et al. [3] proposed that the degraded tie-molecules may then crystallize at the lateral surface of the pre-existing crystallites, leading to an increase in the lateral ACS.

Several authors have proposed mechanisms for the tensile failure of PPTA fibres [6, 1316], based on the different structural models described above. For instance, Hodson et al. [14] distinguished three kinds of tensile failure for Kevlar 49 single filaments. The authors attributed these different failure modes to different crack propagation pathways. The first failure mode involves essentially transverse crack propagation through the fibre skin and core; the resulting tensile break is normal to the fibre axis $[6,13,15]$. The second failure mode involves a complex combination of skin-core transverse and longitudinal crack propagation; the resulting tensile fracture displays axial splitting $[6,13,14]$. The third failure mode is initiated by transverse crack propagation through a portion of the skin, followed by longitudinal crack propagation along the fibre axis. The resulting tensile break presents a skin peeling longitudinally along the fibre axis and separating from the body of the fibre $[6,13$, 14]. Morgan et al. [6] suggested that crack propagation can readily occur in the longitudinal directions because it only requires the rupture of hydrogen bonds. They specified that crack propagation occurs preferentially in the chain-end defect layers after chemical degradation has further weakened these layers via chain scissions.

The present work aims at identifying the structural degradation induced by aging under moderately alkaline conditions. First, X-ray diffraction (XRD) measurements have been carried out to evaluate the changes in the lateral and longitudinal crystallite size. Then, the tensile fracture of aged filaments has been observed by scanning electron microscopy (SEM). Finally, size exclusion chromatography (SEC) has been performed to follow the chain distribution evolutions. 


\section{Experimental}

\subsection{Materials}

The Twaron type 1000 fibre studied in this paper, in the form of 1680 dtex yarn, is a paraaramid fibre produced by Teijin Aramid. Each yarn is composed of 1000 filaments.

\subsection{Aging methods}

Yarns were studied in two aging environments. Yarn samples were immersed in sodium carbonate buffer solutions at $\mathrm{pH} 9$ and $\mathrm{pH} 11$. The $\mathrm{pH}$ was controlled every week. Four temperatures have been considered for each aging condition: $20,40,60$ and $80^{\circ} \mathrm{C}$. Over the aging period considered here the temperature variability is estimated at $\pm 2{ }^{\circ} \mathrm{C}$.

\subsection{Analysis and characterization}

To characterize the crystallite size evolution with aging, both equatorial and meridional XRD patterns of Twaron 1000 fibres were measured. After aging, the fibres were manipulated with particular caution in order to avoid any damage to the filaments.

\section{Wide-angle X-ray diffraction}

\section{Equatorial Scans}

The equatorial intensity was recorded in reflection mode using a Philips PW1830 X-Ray diffractometer in $\theta / 2 \theta$ geometry and a proportional counter. A bundle of parallel yarns carefully laid on a silicon disc was exposed to $\mathrm{CoK}_{\alpha} \mathrm{X}$-Rays with a $2 \theta$ angle varying from 4 to 
$70^{\circ}$. The equatorial diffraction peaks were fitted using a symmetrical Pearson VII function, as applied by Marcellan et al. for polyamide 66 fibres [17]. The apparent crystallite size (ACS) normal to the (110) and (200) planes was evaluated from the full width at half maximum of the resolved peaks using Scherrer's equation [18], in which instrumental peak broadening is taken into account:

$$
A C S_{h k l}=\frac{K \lambda}{\beta_{2 \theta} \cos \theta}
$$

where $A C S_{h k l}$ is the mean dimension of the crystallites perpendicular to the planes $(h k l), \lambda$ is the wavelength (1.7903 $\AA$ for $\mathrm{CoK}_{\alpha}$ radiation), $\beta_{2 \theta}$ is the full width at half maximum (FWHM) of the resolved peaks in radians after correction for instrumental broadening, $\mathrm{K}$ is a constant that is assigned a value of 0.9. Instrumental broadening was measured as function of the diffraction angle using a silicon reference sample. It is taken into account using the Gaussian approximation:

\section{Erreur ! Des objets ne peuvent pas être créés à partir des codes de champs de mise en}

\section{forme.}

where $\beta_{\text {exp }}$ is the observed FWHM width and $\beta_{\text {corr }}$ is the instrumental peak broadening. Measurement of the silicon reference peak at $2 \theta=33.12^{\circ}(2 \theta)$ indicated a value for the instrumental broadening of $0.133^{\circ}$. Since the apparent lateral crystallite sizes are based on equatorial reflections which are much broader than meridional reflections the influence of instrumental broadening is much smaller as compared to the longitudinal apparent crystallite 
sizes. The standard deviations indicated in this study are calculated from a series of three XRD scans per sample.

\section{Meridional scans}

These measurements were carried out on a Bruker D8 Advance diffractometer in $\theta / 2 \theta$ geometry, equipped with parallel beam optics. The optics consist of a primary $60 \mathrm{~mm}$ Göbel focussing mirror (a parabolic $\mathrm{Ni} / \mathrm{C}$ multilayer device) providing $\mathrm{CuK}_{\alpha}$ radiation, and $0.12^{\circ}$ Soller slits. The diffractometer is equipped with scintillation detector and autochanger. After aging, the yarns were wound on a metal frame sample holder using a winding device in which a very low constant tension $(20 \mathrm{mg} / \mathrm{tex})$ is applied, taking care that the filaments are parallel. The meridional diffraction peaks were fitted using an asymmetric Pearson VII function, since instrumental factors (axial divergence) cause asymmetry of the diffraction peaks, especially at low angles. Figure 3 shows the asymmetry of a diffraction peak of a $\mathrm{LaB}_{6}$ powder reference sample (NIST SRM 660). The apparent crystallite size normal to the (002) and (004) planes was evaluated from the full width at half maximum of the peaks using Scherrer's equation (2) in which instrumental peak broadening is taken into account. Instrumental broadening was measured as function of the diffraction angle using the $\mathrm{LaB}_{6}$ reference sample. The instrumental broadening is accounted for using the Gaussian approximation (3). The results are displayed in Figure 4. In order to check the reproducibility of the longitudinal ACS values only the measurements of the aged samples were done twice. 


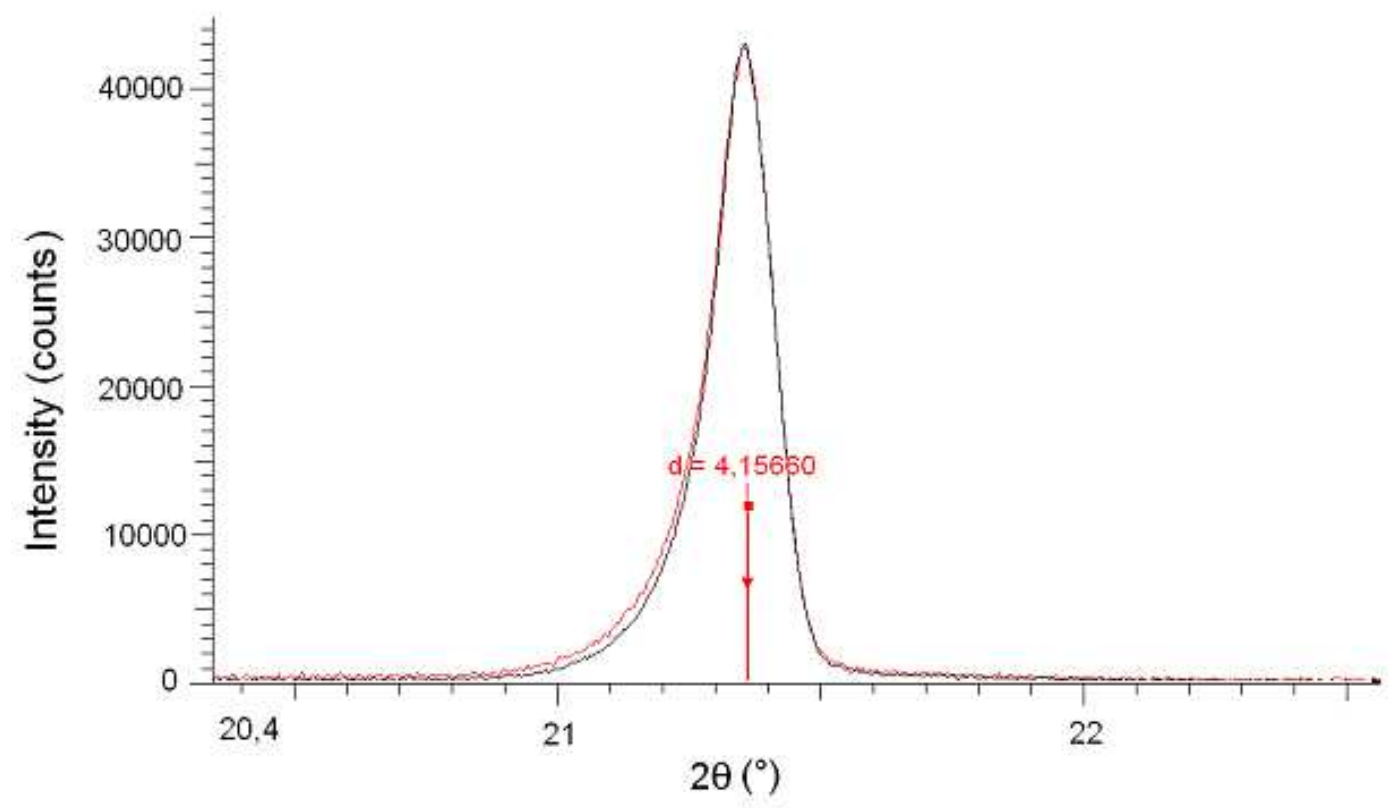

Figure 3: X-ray diffraction scan of the 100 peak of the $\mathrm{LaB}_{6}$ powder reference sample.

Figure 4: Instrumental peak broadening of the D8 Advance diffractometer as function of the diffraction angle, measured using the $\mathrm{LaB}_{6}$ powder reference sample.

$>$ Scanning Electron Microscopy

SEM micrographs of the fibres were obtained in secondary electrons mode, at $12 \mathrm{kV}$ voltage and at a working distance of $10 \mathrm{~mm}$. The fibres were observed by SEM in two ways. First, the sections were examined after two minutes immersion in $96 \% \mathrm{H}_{2} \mathrm{SO}_{4}$, at ambient temperature. These fibres were arranged as parallel bundles and coated in epoxy resin. The samples were then cut perpendicular to the sections of the fibres, polished and coated with gold. The $\mathrm{H}_{2} \mathrm{SO}_{4}$ 
treatment is expected to dissolve the less crystalline regions of Twaron 1000 fibres first. Next, the tensile fracture surfaces were inspected. These filaments had been subjected to tensile loading up to fracture (see below). They were then placed on adhesive carbon tabs, so that the tensile fracture features could be observed, and coated with gold.

\section{Tensile testing}

Single fibres were tested to failure using a Zwick 1474 tensile testing machine with a $5 \mathrm{~N}$ load cell and a rate of extension of $10 \% / \mathrm{min}$, at $20^{\circ} \mathrm{C}$. These tests are described in more details elsewhere [19-21].

\section{Size Exclusion Chromatography}

Size exclusion chromatography was performed by dissolving the sample in concentrated $\mathrm{H}_{2} \mathrm{SO}_{4}(1 \mathrm{mg} / \mathrm{mL})$ and separating this using a modified Zorbax column $(250 \times 6.2 \mathrm{~mm})$ and concentrated $\mathrm{H}_{2} \mathrm{SO}_{4}$ as the mobile phase $(0.1 \mathrm{~mL} / \mathrm{min})$. A UV detector operating at $340 \mathrm{~nm}$ was used. From the chromatograms, the $\mathrm{M}_{\mathrm{w}}$ values were calculated using Cirrus version 1.1 GPC software (Polymer Labs). Four injections per sample were carried out. As references in the SEC analysis, a Twaron (PPTA) yarn, type 1010 and an aramid trimer were used.

\section{Results and discussion}

\subsection{Structure evolution}

\subsubsection{Lateral Apparent Crystallite Size}

First, the lateral apparent crystallite size (ACS) has been determined at different aging times. Table 1 lists the ACS of Twaron 1000 fibres after one year aging under the two alkaline conditions, calculated from equatorial XRD data using the Scherrer equation (2). 
Table 1: Lateral apparent crystallite size of Twaron 1000 fibres after one year aging.

\begin{tabular}{|c|c|c|c|}
\hline & & $\begin{array}{l}\mathrm{ACS}_{110} \\
(\mathrm{~nm})\end{array}$ & $\begin{array}{l}\mathrm{ACS}_{200} \\
(\mathrm{~nm})\end{array}$ \\
\hline \multicolumn{2}{|c|}{ As-received } & $5.83 \pm 0.13$ & $5.27 \pm 0.09$ \\
\hline \multirow{2}{*}{$\mathrm{pH} 9$} & $20^{\circ} \mathrm{C}$ & $6.03 \pm 0.11$ & $5.40 \pm 0.10$ \\
\hline & $80^{\circ} \mathrm{C}$ & $6.24 \pm 0.08$ & $5.44 \pm 0.08$ \\
\hline \multirow{2}{*}{ pH11 } & $20^{\circ} \mathrm{C}$ & $5.93 \pm 0.20$ & $5.37 \pm 0.09$ \\
\hline & $80^{\circ} \mathrm{C}$ & $6.27 \pm 0.04$ & $5.51 \pm 0.02$ \\
\hline
\end{tabular}

It appears that $\mathrm{ACS}_{110}$ and $\mathrm{ACS}_{200}$ both increase after one year under the conditions used in this investigation, the increase being larger at $80^{\circ} \mathrm{C}$ than at $20^{\circ} \mathrm{C}$. The increase in the lateral ACS does not depend strongly on the $\mathrm{pH}$ : it varies from 6 to $7 \%$ for $\mathrm{ACS}_{110}$, and from 3 to $5 \%$ for $\mathrm{ACS}_{200}$, for all conditions. Figure 5 presents the evolution of the lateral $\mathrm{ACS}_{200}$ with time at $\mathrm{pH} 11$.

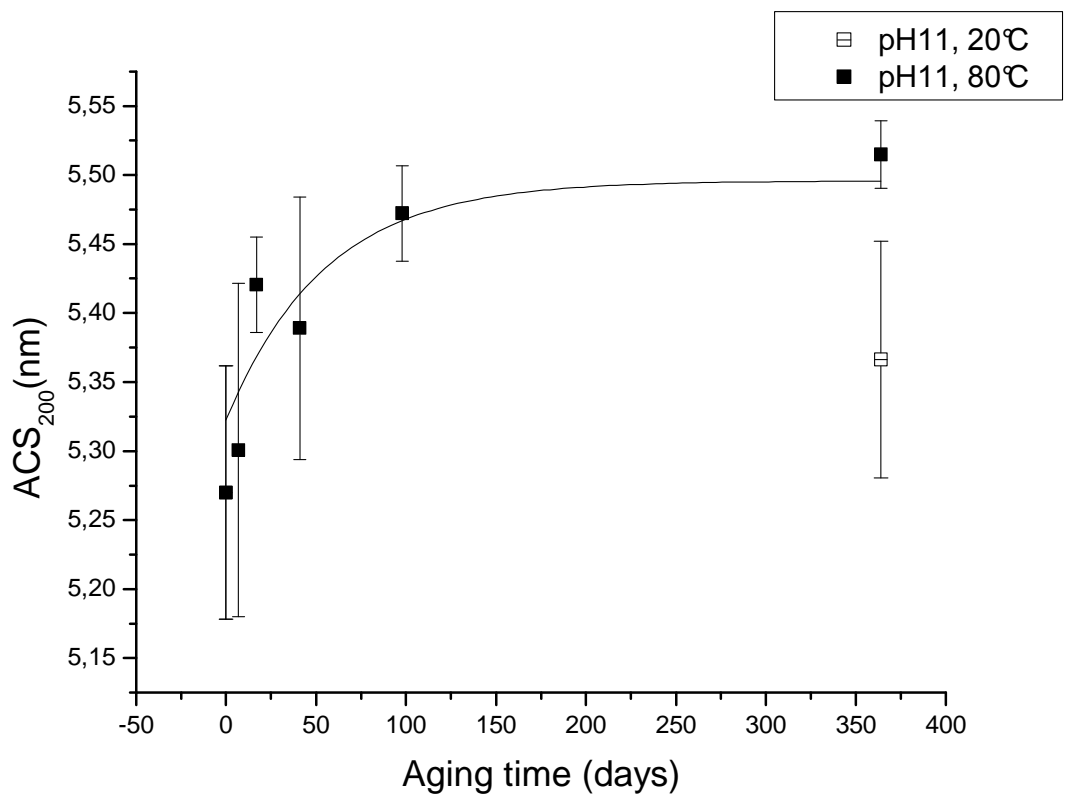

Figure 5: Time evolution of the lateral apparent crystallite size $\mathrm{ACS}_{200}$ upon aging at $\mathrm{pH} 11$, at $20^{\circ} \mathrm{C}$ and $80^{\circ} \mathrm{C}$ respectively. The solid line estimates the ACS evolution at $\mathrm{pH} 11$ and $80^{\circ} \mathrm{C}$. 
For the two temperatures, $\mathrm{ACS}_{110}$ and $\mathrm{ACS}_{200}$ follow the same kind of evolution: they increase roughly from the beginning of aging to 98 days aging and start levelling off until one year aging. It is thus a short-term process.

Fukuda and Kawai [22] studied as spun Kevlar yarn kept in distilled water; this yarn had not received a heat treatment, hence its small (110) apparent lateral crystallite size of $3.3 \mathrm{~nm}$. $\mathrm{Wu}$ and Blackwell [23] report larger (110) apparent lateral crystallite size values (up to 13 nm) measured on Kevlar yarns that did receive a heat treatment. The large range in apparent lateral crystallite sizes found in the literature is due to different processing conditions of the samples investigated. Moreover, the aramid yarns in the present study are not Kevlar but Twaron yarns. Despite the differences between the Kevlar and Twaron processes in terms of polymer characteristics, spinning process and applied heat treatment conditions the lateral crystallite sizes reported in the present study are well within the range of previous reports [2224].

It must be noted that the lateral apparent crystallite size determined here is an estimate of the crystallite size, as lattice distortions are not taken into account in Scherrer's equation [18]. The broadening of reflections is in general due to both size effects and strain effects. The $2 \theta$ dependency of these effects differs. Precisely this different dependency is the basis of methods introduced to separate size broadening from strain broadening, such as the Hosemann method [25] for the determination of the crystallite size and the paracrystalline distortion factor. For aramids it is well known that strain broadening is an important aspect of the diffraction pattern [26]. Strain broadening increases with the order of the reflection, whereas size broadening does not (expressed in terms of the magnitude of the diffraction vector). If higher orders of a reflection are available size broadening can be separated from strain broadening. Unfortunately higher orders are not available in the equatorial diffraction pattern of PPTA 
fibers. Separation of size and strain effects is therefore impossible, which is why we have to resort to apparent lateral crystallite sizes.

It has been shown by Panar et al. [5] that an $80 \%$ nitric acid solvent can penetrate selectively between fibrils. Moreover, Morgan et al. [27] suggested that the water molecules preferentially accumulate in the interfibrillar regions. From these considerations, it is likely that the interfibrillar regions are more exposed to hydrolysis. The increase in the lateral ACS noted in our study could thus be attributed to the degradation of the tie-fibrils introduced by Panar et al. [5] which may recrystallize on the surface of pre-existing crystallites.

Figure 6 presents a representative SEM picture of a cross-section of a Twaron 1000 filament aged for one and a half year at $\mathrm{pH} 11$ and $80^{\circ} \mathrm{C}$, after a $\mathrm{H}_{2} \mathrm{SO}_{4}$ treatment. The picture displays the fibrillar structure described by Panar et al. for PPTA fibres [5]: most of the fibrils are oriented in the fibre direction. This picture also reveals the presence of some lateral "links" that may correspond to the tie-fibrils of the fibrillar structure. It may be noted that some lateral links remain after one and half years at $\mathrm{pH} 11$ and $80^{\circ} \mathrm{C}$.

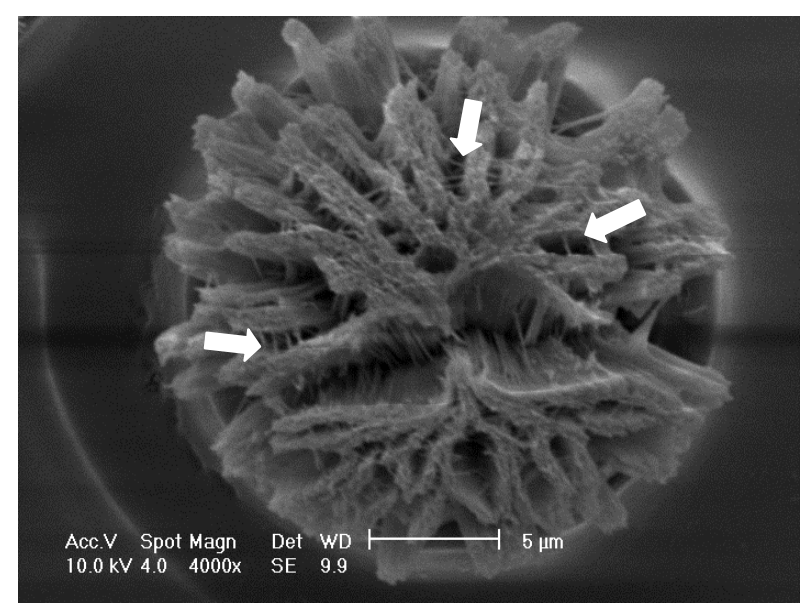


Figure 6: SEM picture of a Twaron 1000 fibre aged for one and half years at $\mathrm{pH} 11$ and $80^{\circ} \mathrm{C}$, after 2 minutes in $96 \% \mathrm{H}_{2} \mathrm{SO}_{4}$ at ambient temperature. The white arrows indicate lateral "links" which may correspond to the "tie-fibrils" proposed by Panar et al. [6].

The increase in the lateral ACS observed here may be due to the degradation of Panar et al.'s tie-fibrils, as discussed above. Alternatively, it could be due to imperfectly crystallized chains located at the surface of the crystallites, and/or to the degradation of "tie-molecules" that would ensure the cohesion between adjacent crystallites. If small crystallites disappear, or more in general, if crystallites with a low crystalline perfection disappear due to degradation the average crystallite size will increase, hence the ACS value will increase.

In order to evaluate whether there is a correlation between the tensile strength and the lateral ACS, the two characteristics have been plotted in Figure 7.

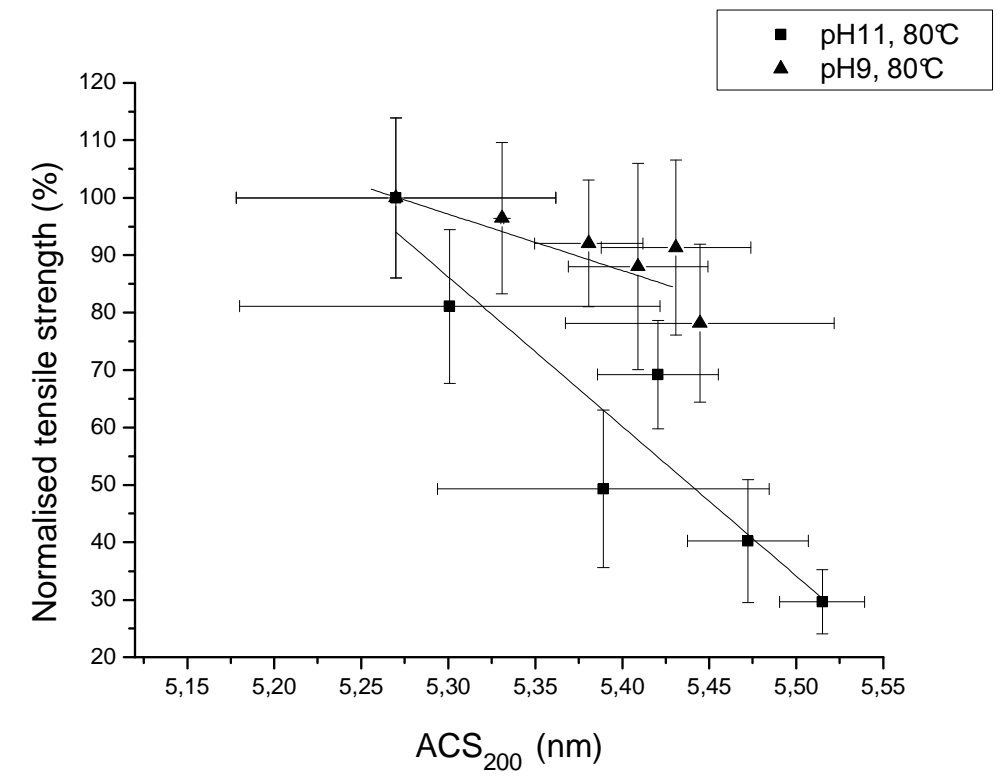

Figure 7: Correlation between the lateral apparent crystallite size $\mathrm{ACS}_{200}$ of hydrolyticallyaged Twaron 1000 fibres. 
The lateral ACS seems to follow, to a first approximation, a linear relation with the tensile strength both at $\mathrm{pH} 9$ and at $\mathrm{pH} 11$. Considering a similar lateral ACS which can be seen as a similar degradation rate of lateral "links" (such as "tie-fibrils") between adjacent crystallites, the tensile strength is lower at $\mathrm{pH} 11$ than at $\mathrm{pH} 9$. This difference may be explained by the degradation of another type of molecules at pH11. Meridional XRD measurements have been carried out to check whether longitudinally-oriented chains are degraded under moderately alkaline conditions.

\subsubsection{Longitudinal apparent crystallite size}

In the longitudinal direction several orders of the 002 reflection are present (i.e. the 004 and 006 reflections). Since the prerequisites (i.e. higher reflection orders) for the Hosemann method are present it has been applied in the literature to determine longitudinal structural parameters of aramids [28]. Yet, application of the Hosemann method to aramids is questionable, as was reported by Krenzer and Ruland [26]. According to these authors the 006 reflection can not be used since it contains a contribution of the 106 reflection. Moreover, Krenzer and Ruland use Warren-Averbach theory to show that a one-dimensional paracrystalline disorder model along the c-axis, as assumed in the Hosemann model, is not justified.

Given the difficulties with the 006 reflection and the controversy in the literature concerning the applicability of the paracrystalline model it was decided to simply use apparent crystallite sizes in the present report and to defer a more involved analysis to a later stage. Table 2 lists the longitudinal ACS of Twaron 1000 fibres after one year aging at pH9 and at pH11 calculated from meridional XRD data using the Scherrer equation (2).

Table 2: Longitudinal Apparent Crystallite Size (ACS) of Twaron 1000 fibres after one year hydrolytic aging. 


\begin{tabular}{|c|c|c|}
\cline { 2 - 3 } \multicolumn{1}{c|}{} & $\begin{array}{l}\mathrm{ACS}_{002} \\
(\mathrm{~nm})\end{array}$ & $\begin{array}{l}\mathrm{ACS}_{004} \\
(\mathrm{~nm})\end{array}$ \\
\hline As-received & 62.7 & 20.9 \\
\hline $\mathrm{pH} 9,80^{\circ} \mathrm{C}$ & 70.0 & 19.5 \\
& 68.9 & 19.3 \\
\hline $\mathrm{pH} 11,80^{\circ} \mathrm{C}$ & 62.5 & 18.9 \\
& 61.5 & 18.7 \\
\hline
\end{tabular}

It may be noted that $\mathrm{ACS}_{002}$ obtained from meridional scans is about ten times larger than the lateral ACS determined from equatorial scans, which is in accordance with other studies $[29,30]$. These results reveal that both $\mathrm{ACS}_{002}$ and $\mathrm{ACS}_{004}$ decrease slightly (respectively by $\sim 0.3 \%$ and $\sim 9.6 \%$ ) after one year at $\mathrm{pH} 11$ and $80^{\circ} \mathrm{C}$. This would be consistent with the degradation of the tie-molecules passing through consecutive crystallites, as proposed by Springer et al. [3]. This assumption is supported by Panar et al. who suggested that the chainend defects layers are more permeable to protons and are susceptible to be hydrolysed [5]. Indeed, these authors reported that the average length of PPTA chains hydrolysed with hydrochloric acid corresponds to the periodic spacing detected by electron microscopy attributed to the chain-end defects layers [5].

After one year at $\mathrm{pH} 9$ and $80^{\circ} \mathrm{C}$, the evolution of the longitudinal ACS is different according to whether $\mathrm{ACS}_{002}$ or $\mathrm{ACS}_{004}$ is considered. Indeed, for these conditions, $\mathrm{ACS}_{002}$ increases by $\sim 11.6 \%$ whereas $\mathrm{ACS}_{004}$ decreases by $\sim 6.7 \%$. In any case it turns out that the crystal size is lower at $\mathrm{pH} 11$ than at $\mathrm{pH} 9$.

To support these interpretations, tensile fracture surfaces of aged Twaron 1000 fibres have been investigated by SEM.

\subsection{Tensile fracture}


SEM pictures of representative single fibre tensile breaks of as-received and hydrolyticallyaged Twaron 1000 fibres are shown in Figure 8. From this figure it is clear that the mechanisms involved in tensile fracture depend on the aging condition and time. Broken samples of as-received Twaron 1000 filaments display axial splitting, as observed by Bunsell for Kevlar 49 fibres [31]. In a similar way, Hearle et al. [32] reported that Kevlar 29 and Kevlar 49 are characterized by fibrillar tensile failure. The fracture surfaces of Twaron 1000 filaments aged for one and a half years at $\mathrm{pH} 9$ and $80^{\circ} \mathrm{C}$ still display axial splitting, but the splits are on average shorter than those of the as-received fibres. The fracture surfaces of Twaron 1000 filaments aged for one and half years at $\mathrm{pH} 11$ and $80^{\circ} \mathrm{C}$ are quite different; splitting is not observed and the fracture planes are perpendicular to the fibre axis. A SEM picture at a higher magnification is shown in Figure 9. 


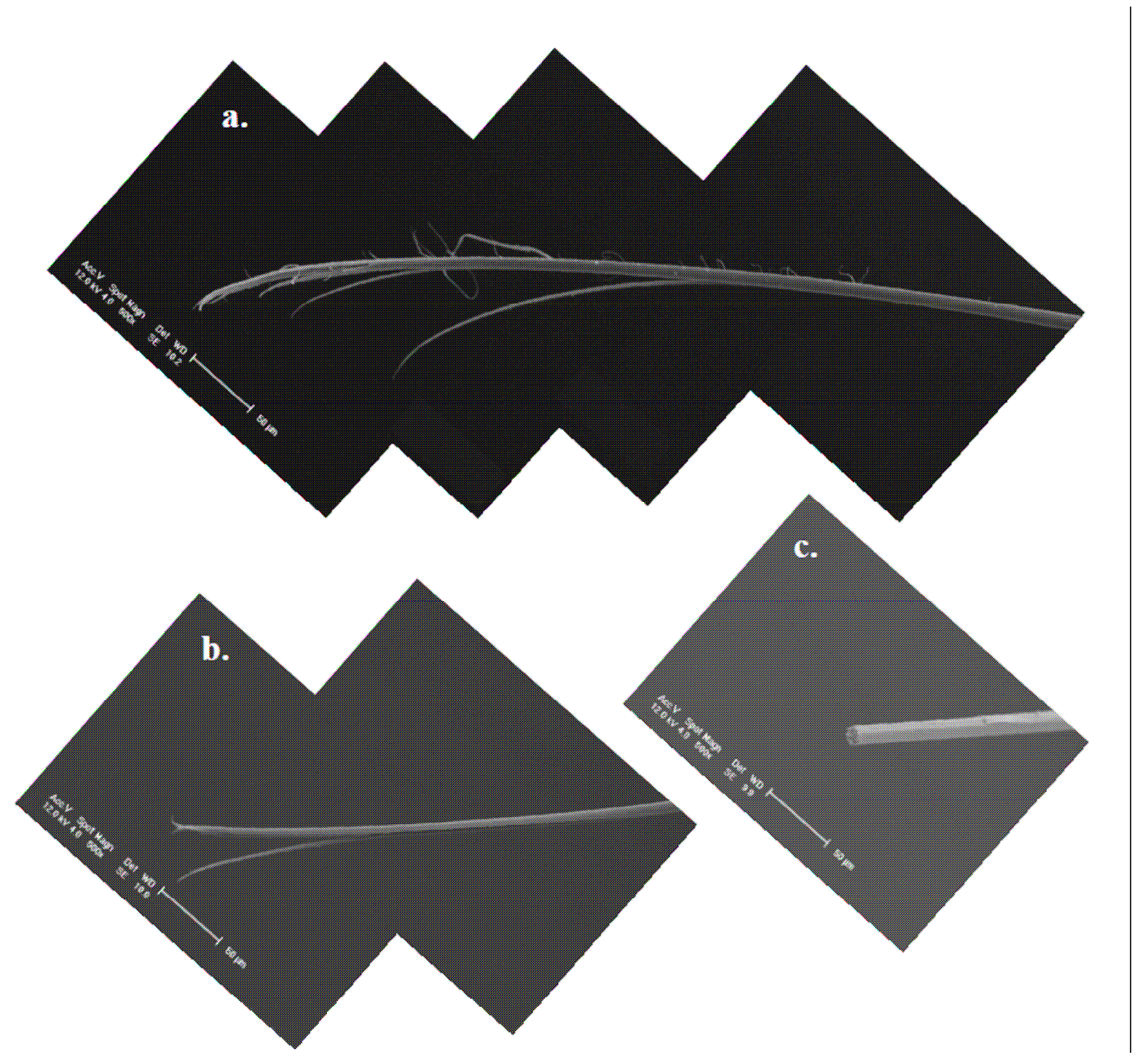

Figure 8: SEM pictures of the tensile breaks of Twaron 1000 fibres (a) as-received, (b) after one and half years at $\mathrm{pH} 9$ and $80^{\circ} \mathrm{C}$ and (c) after one and half years at $\mathrm{pH} 11$ and $80^{\circ} \mathrm{C}$. The pictures have been taken with the same magnifying power $(\times 500)$ 


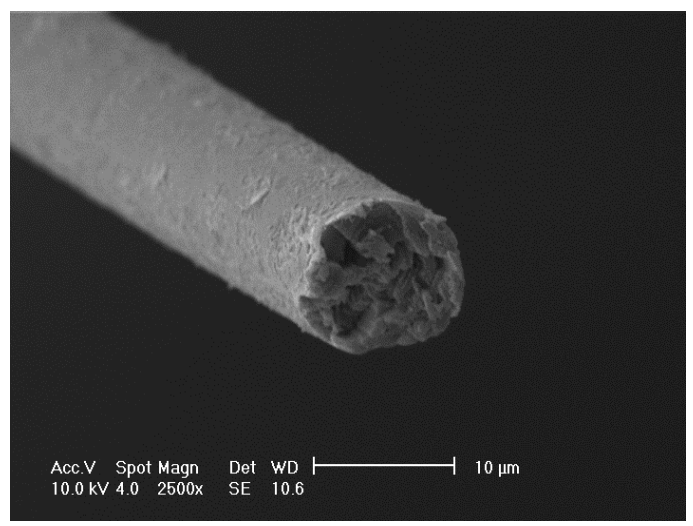

Figure 9: SEM picture of the tensile fracture of Twaron 1000 filament after one and half years aging at $\mathrm{pH} 11$ and $80^{\circ} \mathrm{C}($ magnification $\times 2500)$

The SEM results indicate that the fibres aged at $\mathrm{pH} 11$ and $80^{\circ} \mathrm{C}$ for one and half years fail through crack propagation in a number of parallel planes perpendicular to the fibre axis. These features have been previously observed by $\mathrm{Li}$ et al. [7] for $\mathrm{HCl}$-etched Kevlar fibres, by

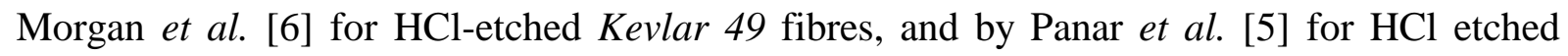
PPTA fibres, with a minimum step between the planes varying from 200 to $300 \mathrm{~nm}$. Li et al. [7] and Morgan et al. [6] reported that this spacing corresponds to the crystallite thickness, and Panar et al. [5] reported that it is consistent with the distance between the pleats of the pleated sheet structure.

The tensile failure observed in this study appears to be consistent with X-ray diffraction results. At $\mathrm{pH} 11$, the degradation of the tie-molecules in the chain-end defect layers may favour the transverse crack propagation resulting in tensile breaks normal to the fibre axis. At $\mathrm{pH}$, the tensile breaks remain fibrillar, indicating that longitudinal crack propagation may still be predominant. However, as the observed split lengths are shorter than for as-received fibres, some minor transverse crack propagation may still occur due to the slight degradation of the tie-molecules between consecutive crystallites. To further examine these interpretations, SEC analyses have been performed. 


\subsection{Mass distribution evolution}

The average molecular masses and the polydispersity indices of Twaron 1000 fibres before and after one and half years aging in moderately alkaline environments are grouped in Table 3. The corresponding chromatograms are shown in Figure 10.

Table 3: Molecular masses and polydispersity indexes of as-received and hydrolytically- aged fibres, obtained from SEC analyses.

\begin{tabular}{|c|c|c|c|c|}
\cline { 2 - 5 } \multicolumn{1}{c|}{} & $\mathrm{M}_{\mathrm{n}}$ & $\mathrm{M}_{\mathrm{w}}$ & $\mathrm{M}_{\mathrm{z}}$ & $\mathrm{D}$ \\
\hline As-received & 10900 & 32900 & 54000 & 3.0 \\
\hline $\mathrm{pH} 9,80^{\circ} \mathrm{C}, 549$ days & 8600 & 26600 & 44000 & 3.1 \\
\hline $\mathrm{pH} 11,80^{\circ} \mathrm{C}, 549$ days & 4300 & 14000 & 23000 & 3.3 \\
\hline
\end{tabular}

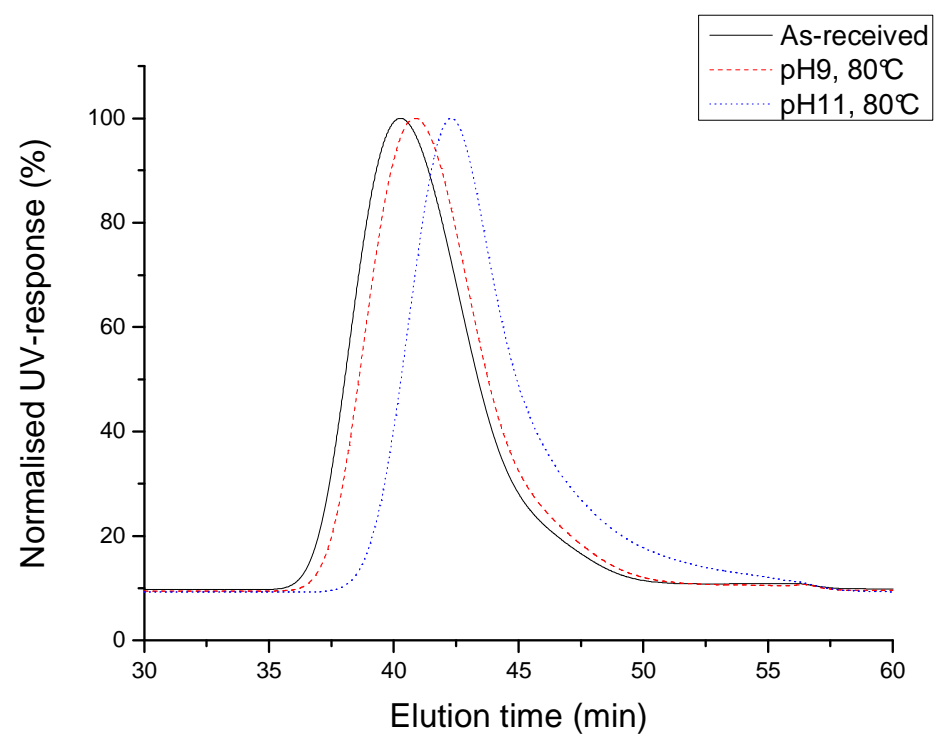

Figure 10: Chromatograms of as-received and hydrolytically-aged Twaron 1000 fibres. 
The $\mathrm{M}_{\mathrm{w}}$ evolutions are consistent with the viscosity measurements from a previous study [21]. The degradation is significantly higher at $\mathrm{pH} 11$ than at $\mathrm{pH} 9$. As for the polydispersity index (D), it remains constant at pH9, but it increases slightly at pH11.

A superposition of representative chromatograms of as-received fibres and fibres aged at $\mathrm{pH} 11$ and $80^{\circ} \mathrm{C}$ for one and half years is given in Figure 11 . The mass distributions of asreceived fibres and of fibres aged at $\mathrm{pH} 9$ and $80^{\circ} \mathrm{C}$ are similar.

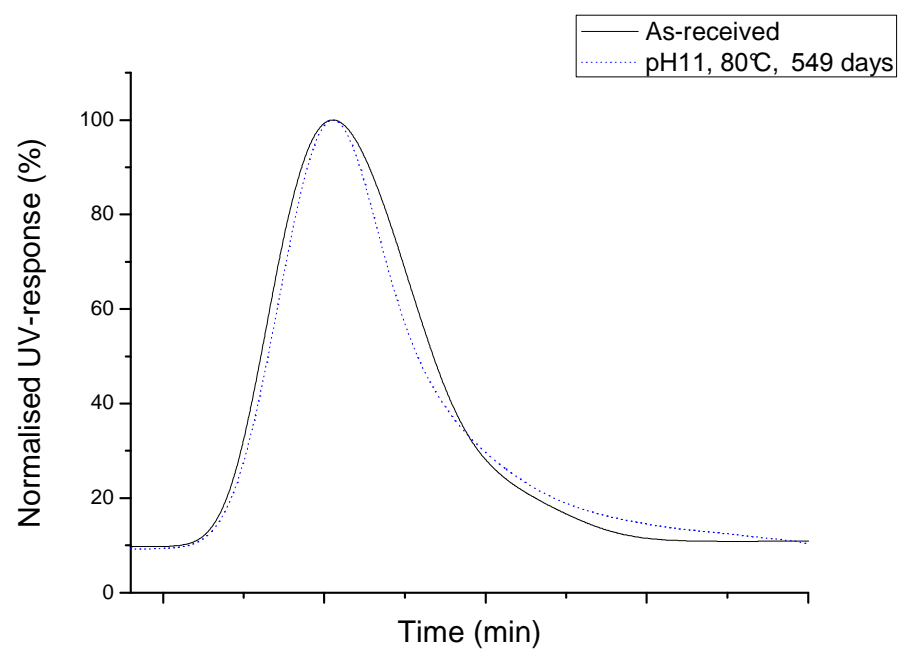

Figure 11: Superposition of the chromatograms of as-received and aged Twaron 1000 fibres. The elution times indicated on the $\mathrm{x}$-axis are arbitrary.

After one and half years aging at $\mathrm{pH} 11$ and $80^{\circ} \mathrm{C}$, it may be noted that the main distribution gets narrower. This observation would be consistent with the degradation of the tie-molecules passing through consecutive crystallites, as proposed from the meridional X-Ray Diffraction results. These tie-molecules may be longer polymer chains, for which the length tends to reach the average length of the crystallized chains as the degradation progresses, resulting in a slightly narrower mass distribution. However, it can be noted that the polydispersity index increases slightly under these conditions. Actually, it appears that the distribution tail spreads slightly. Smaller polymer chain fractions have thus been generated after one and half years 
aging at $\mathrm{pH} 11$ and $80^{\circ} \mathrm{C}$. As the chain-end defects layers described in different structural models [5-7] are more exposed to hydrolysis [5], the smaller chain fractions observed at pH11 may be attributed to some degraded chain ends. Thereby, the chain ends scission may enhance the water molecule penetration into the chain-end layers, and thus favour hydrolysis of the tiemolecules passing through consecutive crystallites. This may explain why the degradation of the tie-molecules passing through consecutive crystallites is higher at $\mathrm{pH} 11$ than at $\mathrm{pH} 9$, as deduced from X-Ray Diffraction measurements. Moreover, it must be mentioned that the higher concentration of hydroxide at $\mathrm{pH} 11$ may accelerate the degradation kinetics, which would explain the difference in the structural degradation observed at $\mathrm{pH} 9$ and at $\mathrm{pH} 11$.

A previous study has shown that in moderate alkaline environments $(\mathrm{pH} 9$ and $\mathrm{pH} 11)$ the chemical degradation of Twaron 1000 fibres can be fitted by Springer et al.'s equation (1), using one decay function at $\mathrm{pH} 9$ and two decay functions at $\mathrm{pH} 11$ [21]. We assumed thus that the degradation may be attributed to one degradation process at $\mathrm{pH} 9$ and two degradation processes at $\mathrm{pH} 11$. From the results presented here, we propose that the processes involved at pH11 may be on one hand the degradation of tie-molecules/fibrils, and on the other the degradation of the crystallites themselves in the chain-end defects layers. At pH9, the degradation of the tie-fibrils and, to a lower extent, the degradation of the tie-molecules between consecutive crystallites is proposed.

\section{Conclusions}

Within the framework of a durability study, Twaron 1000 fibres have been aged at $\mathrm{pH} 9$ and $\mathrm{pH} 11$ at temperatures ranging from 20 to $80^{\circ} \mathrm{C}$. The structural characteristics (lateral and longitudinal apparent crystallite size) have been determined by Wide-Angle X-ray diffraction after different aging times. Size exclusion chromatography analyses and SEM observation of 
the tensile breaks suggest that the scheme proposed below may explain the structural degradation:

- At pH11, the degradation of lateral "links" between adjacent crystallites, such as the tie-fibrils, is accompanied by the degradation of the tie-molecules passing through consecutive crystallites. Smaller chain fractions, which may be attributed to some degraded crystalline fractions such as the chain-ends, are generated under this condition.

- At pH9, the hydrolytic degradation of lateral "links" between adjacent crystallites, such as the tie-fibrils, may occur. The degradation of the tie-molecules passing through consecutive crystallites may operate as well but to a lesser extent than at pH11.

These structural features have been shown to be closely related to the tensile strength of the fibres. For example, a linear correlation can be made between the lateral crystallite size and the tensile strength. The influence of other structural characteristics, such as changes in porosity, is currently being studied.

\section{Acknowledgements}

The authors are grateful to Otto Grabandt (Teijin Aramid) for the fibre samples and his support. The authors acknowledge the contributions of Nicolas Barberis, Dominique Duragrin, Arnaud Plantet, (LCPC Paris) and Nicolas Lacotte (IFREMER Brest) to the aging and characterization studies presented here. Special thanks are due to Alba Marcellan (ESPCI) and Frédéric Boinski (LCPC Paris) for the very constructive discussions. 


\section{References}

1. Yang HH (1993) Kevlar Aramid Fiber. John Wiley \& Sons

2. Morgan RJ, Pruneda CO, Butler N, Kong F-M., Caley L, Moore RL (1984) The hydrolytic degradation of Kevlar 49 fibers. Proceedings of the $29^{\text {th }}$ National SAMPE Symposium: 891-900

3. Springer H, Abu Obaid A, Prabawa AB, Hinrichsen G (1998) Influence of Hydrolytic and Chemical Treatment on the Mechanical Properties of Aramid and Copolyaramid Fibers. Textile Research Journal 8(68): 588-594

4. Mercier JP, Maréchal E (1993) Chimie des polymères: synthèses, réactions, degradations. Presses Polytechniques et Universitaires Romandes: 393-395

5. Panar M, Avakian P, Blume RC, Gardner KH, Gierke TD, Yang HH (1983) Morphology of Poly(p-phenylene Terephthalamide) Fibers. Journal of Polymer Science: Polymer Physics Edition 21: 1955-1969

6. Morgan RJ, Pruneda CO, Steele WJ (1983) The Relationship between the Physical Structure and the Microscopic Deformation and Failure Processes of Poly(p-phenylene Terephthalamide) Fibers. Journal of Polymer Science: Polymer Physics Edition 21: $1757-1783$

7. Li L-S, Allard LF, Bigelow WC (1983) On the Morphology of Aromatic Polyamide Fibers (Kevlar, Kevlar-49, and PRD-49). Journal of Macromolecular Science - Physics B22(2): 269-290

8. Dobb MG, Johnson DJ, Saville BP (1977) Direct observation of structure in highmodulus aromatic fibers. Journal of Polymer Science: Polymer symposium 58: 237251

9. Dobb MG, Johnson DJ, Saville BP (1977) Supramolecular Structure of a HighModulus Polyaromatic Fiber. Journal of Polymer Science: Polymer Physics Edition, 15: 2201-2211

10. Dobb MG, Robson RM (1990) Structural characteristics of aramid fibres variants. Journal of Materials Science 25(1B): 459-464

11. Pruneda CO, Morgan RJ, Kong F-M, Hodson JA, Kershaw RP, Casey AW (1984) The modes of deformation and failure of Kevlar 49 fibres and composites. Proceedings of the $29^{\text {th }}$ National SAMPE Symposium: 1213-1221

12. Riekel C, Dieing T, Engström P, Vincze L, Martin C, Mahendrasingam A (1999) Xray Microdiffraction Study of Chain Orientation in Poly( $p$-phenylene terephtalamide). Macromolecules 32: 7859-7865. 
13. Roth S, Burghammer, Janotta A, Riekel C (2003) Rotational Disorder in Poly(pphenylene terephtalamide) Fibers by X-ray Diffraction with a $100 \mathrm{~nm}$ Beam. Macromolecules 36: 1585-1593.

14. Hodson JA, Pruneda CO, Kershaw RP, Morgan RJ (1983) The Deformation and Failure Processes of Kevlar 49 Single Filaments. Composite Technology Review 5(4): $115-117$

15. Konopasek L, Hearle JWS (1977) The Tensile Fatigue Behavior of para-Oriented Aramid Fibers and Their Fracture Morphology. Journal of Applied Polymer Science 21: $2791-2815$

16. Lee JS, Fellers JF, Tang MY, Lin JS (1985) A Dynamic Small Angle X-Ray Scattering of Stressed Kevlar 49/Epoxy Composites. Journal of Composite Materials, 19(2): 114-137

17. Marcellan A, Bunsell AR, Laiarinandrasana L, Piques R (2006) A multi-scale analysis of the microstructure and the tensile mechanical behaviour of polyamide 66 fibre. Polymer 47: 367-378.

18. Alexander LE (1969) X-Ray Diffraction Methods in Polymer Science. WileyInterscience.

19. Derombise G, Vouyovitch Van Schoors L, Davies P (2009) Hydrolytic degradation of Technora fibres in an alkaline and neutral environment: identification of aging indicators. Polymer Degradation and Stability 94(10): 1615-1620

20. Derombise G, Vouyovitch Van Schoors L, Messou M-F, Davies P (2010) Influence of finish treatment on the durability of aramid fibres aged under an alkaline environment. Journal of Applied Polymer Science 117(2): 888-898.

21. Derombise G, Vouyovitch Van Schoors L, Davies P (2010) Degradation of aramid fibres under alkaline and neutral conditions: relations between physico-chemical characteristics and mechanical properties. Journal of Applied Polymer Science 116(5): 2504-2514.

22. Fukuda M, Kawai H (1997) Moisture Sorption Mechanism of Aromatic Polyamide Fibers .5. Growth of Crystallites in as-Spun Wet Poly(P-Phenylene Terephthalamide) Fiber During Dehydration. Journal of Polymer Science Part B: Polymer Physics 35(9): 1423-1432.

23. Wu TM, Blackwell J (1996) Comparison of the Axial Correlation Lengths and Paracrystalline Distortion for Technora and Kevlar Aromatic Polyamide Fibers. Macromolecules 29(17): 5621-5627.

24. Hindeleh AM, Halim NA, Ziq KA (1984) Solid-State Morphology and Mechanical properties of Kevlar 29 fiber. Journal of Macromolecular Science - Physics B23(3): 289-309

25. Hosemann R (1986) Microparacrystals in PPTA fibers in thermodynamic equilibrium state. Colloid \& Polymer Science 264(4): 332-334. 
26. Krenzer E, Ruland W (1985) Lattice defects in poly(p-phenylene-terephthalamide) fibers. Colloid \& Polymer Science 263(7): 554-562.

27. Morgan RJ, Pruneda CO (1987) Characterization of chemical impurities in Kevlar 49 fibres. Polymer 28: 340-346

28. Barton RJ (1985) Paracrystallinity-modulus relationships in Kevlar aramid fibers. Journal of Macromolecular Science B 24: 119-130.

29. Rao Y, Waddon AJ, Farris RJ (2001) Structure-property relation in poly(pterephthalamide) (PPTA) fibers. Polymer 42: 5937-5946

30. Rao Y, Waddon AJ, Farris RJ (2001) The evolution of structure and properties in poly(p-phenylene terephthalamide) fibers. Polymer 42: 5925-5935

31. Bunsell AR (1975) The tensile and fatigue behaviour of Kevlar-49 (PRD-49) fibre. Journal of Materials Science 10: 1300-1308.

32. Hearle JWS, Lomas B, Cooke WD (1998) Tensile Failures. Atlas of fibre fracture and damage to textiles. Woodhead Publishing Ltd: 35-68 